STUDI

FRANCESI

\section{Studi Francesi}

Rivista quadrimestrale fondata da Franco Simone

168 (LVI | III) | 2012

Varia

\title{
Tania Collani, Le Merveilleux dans la prose surréaliste européenne
}

\section{Fabio Scotto}

\section{(2) OpenEdition}

1 Journals

\section{Edizione digitale}

URL: http://journals.openedition.org/studifrancesi/3831

DOI: 10.4000/studifrancesi.3831

ISSN: 2421-5856

\section{Editore}

Rosenberg \& Sellier

\section{Edizione cartacea}

Data di pubblicazione: 1 décembre 2012

Paginazione: 604

ISSN: 0039-2944

\section{Notizia bibliografica digitale}

Fabio Scotto, «Tania Collani, Le Merveilleux dans la prose surréaliste européenne», Studi Francesi [Online], 168 (LVI | III) | 2012, online dal 30 novembre 2015, consultato il 08 mars 2021. URL: http:// journals.openedition.org/studifrancesi/3831 ; DOI: https://doi.org/10.4000/studifrancesi.3831

Questo documento è stato generato automaticamente il 8 mars 2021.

\section{(c) (i) (9)}

Studi Francesi è distribuita con Licenza Creative Commons Attribuzione - Non commerciale - Non opere derivate 4.0 Internazionale. 


\title{
Tania Collani, Le Merveilleux dans la prose surréaliste européenne
}

\author{
Fabio Scotto
}

\section{NOTIZIA}

TANIA COLlani, Le Merveilleux dans la prose surréaliste européenne, Paris, Hermann, 2010

(«Savoir Lettres»), pp. 512.

1 Il ricco studio che Tania Collani, insegnante di Letterature Comparate all'Université de Haute-Alsace, dedica al tema del meraviglioso nella prosa surrealista costituisce una tappa significativa dell'evoluzione degli studi sull'argomento, non soltanto per l'ampiezza della materia trattata e per la vasta «Bibliographie» (pp. 463-499), articolata secondo una ripartizione fra studi teorici surrealisti, proposti singolarmente, e studi critici successivi sugli stessi, ma anche per l'attenzione all'analisi dei testi del corpus, sensibile alle implicazioni semantico-retoriche e fono-prosodiche, a mostrare lo stretto legame fra forma adottata e intenzione autoriale.

2 Nell'«Introduction» (pp.11-18), l'A. fa rilevare il mutare delle definizioni di merveilleux parallelo all'evoluzione del Surrealismo, anche inducendo il lettore a guardarsi da taluni rischi insiti nella tendenza a far coincidere le poetiche di chi abbia effettivamente aderito al movimento e quelle di chi (come Gracq, Bataille, Michaux), più o meno accosto che fosse alle attività del gruppo, non vi abbia mai aderito; di qui la scelta di articolare lo studio sui tre assi complementari storico, teorico e analitico, al fine di dar conto, nell'ordine, del fenomeno in ambito europeo, delle sue basi teoriche e della teoria dell'immagine, così come del récit surrealista, incentrando l'analisi solo sui surrealisti ufficialmente riconosciuti come tali. L'accostamento del merveilleux esaltato da Breton nel Manifeste du surréalisme alla prosa, specie al romanzo, da questi ritenuto un genere inferiore, pone non pochi problemi, ma Collani, anche valendosi degli studi sul romanzo surrealista di John-Herbert Matthews e di Jacqueline Chénieux-Gendron 
legittimanti questo oggetto di studio, affronta la questione unendo efficacemente l'approccio storico e la pratica analitica.

Il primo capitolo «Le surréalisme en Europe (1922-1940). Évolution et expansion d'un mouvement: de l'individuel au collectif» (pp.19-108) mostra l'evoluzione storica del movimento nei vari Paesi europei, dall'Est all'area mediterranea, mettendo in luce il ruolo del merveilleux nella fase di trasformazione della prassi surrealista in rivoluzione sociale dai tratti etico-politici. Il secondo capitolo «Théorisation surréaliste du merveilleux» (pp. 109-204) individua in Leiris e Mabille i due teorizzatori del merveilleux surrealista, il primo nel suo Essai sur le merveilleux (1926) che conferisce ad esso un ruolo centrale nel surrealismo e nell'attività umana le cui ascendenze sono da ricercarsi in Nodier e nel romanzo gotico anglosassone; il secondo per i suoi due fondamentali studi Le Miroir du Merveilleux (1940) e Le Merveilleux (1946), i quali, evidenziando la matrice alchemico-matematica del linguaggio, fanno del "merveilleux" un mito collettivo che ricorre al sillogismo linguistico per restituire alla magia verbale più che al pensiero l'energia vitale della creazione, come avviene nell'eccentrico Pierre Brisset. Ne risulta una tensione che cerca di mediare fra istanze individuali e collettive e situa con Aragon e Desnos la modernità nell'ossimoricità di un «merveilleux concret» (p.170) più prossimo all'immanente, ovvero un merveilleux, per così dire, "anti-astrattivo" (p. 175), in ciò distante dal fantastique, per lo più inteso dai surrealisti come fittizio e non rivelatore in sé.

4 Ritenuto da René Passeron come la «catégorie esthétique extrême du surréalisme» (p. 183), il merveilleux è nel terzo capitolo «Ésthétique et poétique de l'image: mythe et modernité dans le merveilleux surréaliste» (pp. 205-266) immagine contrapposta al simbolo e al suo mistero, come è riscontrabile ad esempio nell'arbitrarietà di senso di certi versi di Éluard (pp. 235-236).

5 Il quarto capitolo «Les récits surréalistes (1922-1945): critères et caractères» (pp. 267384) e il quinto «Le merveilleux surréaliste et les récits: une analyse» (pp. 385-456) propongono un ampio spettro di autori ed esempi testuali, mostrando metodo e perspicuità analitica utili a focalizzare nella loro varietà e complessità le diverse produzioni in esame.

6 Alla summenzionata Bibliografia s'aggiungono in coda una «Conclusion» (pp. 457-462), che individua «la clé du merveilleux surréaliste dans les voies infinies qui s'ouvriront à son [du lecteur] désir et à sa volonté de connaissance», un «Index des noms, des œuvres et des idées» (pp. 501-506) e una «Table des illustrations» (p. 507). 